\title{
SISTEM INFORMASI PENJUALAN MEUBEL CV MANDIRI FURNITURE BERBASIS JAVA
}

\author{
Wahyu Indriyanto ${ }^{1}$, Laksana Priyo Abadi $^{2}$, Adhityo Kuncoro ${ }^{3}$ \\ Program Studi Informatika, Fakultas Teknik dan Ilmu Komputer, Universitas Indraprasta PGRI \\ Jalan Raya Tengah No 80, Kelurahan Gedong, Pasar Rebo, Jakarta Timur \\ wahyu_indriyanto@ymail.com ${ }^{1}$, laksanarioabadi@gmail.com ${ }^{2}, \underline{\text { adhityokuncoro@yahoo.com }}^{3}$
}

\begin{abstract}
Abstrak
Permasalahan dari sistem penjualan mebeul di CV Mandiri Furniture yaitu lambatnya pencarian pendataan barang, data customer, serta proses laporan stok barang dan proses penjualan yang diakibatkan karena sistem yang diterapkan masih bersifat manual dan belum terkomputerisasi. Seiring dengan semakin canggihnya teknologi yang berkembang, komputer telah mendorong terjadinya perubahan ilmu, baik dalam kajian ataupun implementasi dilapangan. Peran teknologi komputer sangat diperlukan oleh berbagai perusahaan. Mengingat kebutuhan akan peningkatan efisiensi dan efektifitas dari setiap kegiatan dalam instansi tidak dapat diukur dan dilakukan secara cepat dan akurat tanpa adanya dukungan teknologi tersebut. Akurasi data, kecepatan waktu dan relevansi menjadi penentu kualitas informasi yang dihasilkan. Tujuan dari sistem ini untuk mempercepat dalam pencarian data barang, data customer, serta proses laporan stok barang dan laporan penjualan. Dengan menggunakan metode pengembangan sistem yaitu Waterfall dalam penelitian ini adalah dengan tahapan-tahapan seperti rekayasa sistem, analisis, desain, coding, testing, dan maintenance. Hasil dari penelitian ini adalah menciptakan aplikasi untuk penjualan mebel yang efektif dan efisien.
\end{abstract}

Kata Kunci: Sistem informasi, Penjualan, Mebel, Java

\begin{abstract}
Problems of the sales system in CV Mandiri Furniture is slow search of data collection, customer data, as well as the process of stock reports of goods and sales process that caused because the system applied is still manual and yet Computerized. As the technology grows, the computer encourages the changing of knowledge, whether in the study or implementation of field. The role of computer technology is indispensable by various companies. Given the need for increased efficiency and effectiveness of each activity in the institution cannot be measured and done quickly and accurately without the support of such technology. Data accuracy, time speed and relevance become the quality determinant of the generated information. The purpose of this system is to accelerate in the search of goods data, customer data, as well as the process of stock reports of goods and sales reports. By using the system development method that is Waterfall in the research is with stages such as system engineering, analysis, design, coding, testing, and maintenance. The result of this research is creating applications for the sale of furniture that is effective and efficient.
\end{abstract}

Keywords: Information System, Sales, Furniturel, Java

\section{PENDAHULUAN}

Toko Mebeul CV. Mandiri Furniture adalah sebuah toko yang menjual berbagai perlengkapan rumah yang mencakup semua barang seperti kursi, lemari dan meja. CV. Mandiri Furniture mempunyai omset yang lumayan besar, namun pengelolaan toko ini masih bersifat manual dengan menggunakan buku sebagai media pencatat proses yang ada di CV. Mandiri Furniture, dan struktur data toko di rasa belum terstruktur secara rapih, sehingga toko ini sering mengalami hambatan dalam laporan proses transaksi penjualan, kontrol jumlah barang yang masuk, dan barang yang keluar. Terkadang karyawan yang sibuk membuat laporan membuat mereka lupa untuk menulis transaksi yang terjadi, ataupun lupa mengecek jumlah barang stok lama dan stok baru yang masuk. Pada saat melakukan transaksi sering 
terjadi keterlambatan dan kesalahan dalam pemberian harga suatu barang tidak tersedianya informasi mengenai harga barang tersebut.

Perancangan sistem administasi toko ini dibuat adalah untuk memudahkan pengelola dalam pendataan perputaran barang dan uang setiap harinya serta memudahkan dalam proses transaksi jual beli dengan costumer agar kemajuan toko lebih terpantau secara akurat. Karena menggunakan buku dan kertas sebagai media pencatatan pengelolaan toko masih kurang efektif dan aman, sehingga di khawatirkan ada catatan yang hilang dan bisa mengganggu kearsipan dari toko tersebut, dan akan mempengaruhi dalam pemantauan perkembangan toko, sehingga di perlukan sebuah sistem administrasi yang terkomputerisasi untuk memudahkan kerja dari pengelola toko. Sistem adalah merupakan suatu bentuk integrasi antara satu komponen dengan komponen lain karena sistem memiliki sasaran yang berbeda untuk setiap kasus yang terjadi dalam sistem tersebut (Sutabri, 2012). Penjualan adalah bagian dari promosi dan promosi adalah salah satu bagian dari keseluruhan sistem pemasaran. Penjualan merupakan pendapatan yang diperoleh dari menjual barang yang mana jumlah yang dibebankan kepada pembeli untuk barang dagang yang diserahkan merupakan pendapatan perusahaan yang bersangkutan (Tantri, 2016).

Sistem informasi merupakan elemen penting dalam proses bisnis yang mempengaruhi pendapatan dari suatu perusahaan. Sehingga perlu dilakukan proses audit pada sistem penjualan tunai agar penjualan pada CV. Mandiri Furniture dapat berjalan dengan dan lebih mudah. Dengan memanfaatkan sistem administrasi aplikasi ini, diharapkan pendataan akan jauh lebih akurat, tepat, dan efisien. Perolehan informasi juga akan lebih cepat di bandingkan dengan cara manual menggunakan buku, mudahmudahan rancangan aplikasi administrasi toko ini dapat terus dikembangkan dan bisa di gunakan pada toko-toko di Indonesia.

\section{PENELITIAN YANG RELEVAN}

Dalam penelitian yang berjudul Pembuatan Sistem Informasi Penjualan Pada Toko Sehat Jaya Elektronik Pacitan dengan peneliti yang bernama Ika Nur Indah memiliki hasil penelitian Sistem Informasi merupakan peranan sangat penting dalam kegiatan bisnis di suatu perusahaan. Toko Sehat Jaya Elektronik masih menggunakan cara yang konvensional dalam mengolah data tentang transaksi penjualan, untuk itu membutuhkan sistem informasi yang dapat menunjang kelancaran dalam melakukan transaksi penjualan. Tujuan dari penelitian ini merupakan upaya untuk membuat sistem informasi di Toko Sehat Jaya Elektronik yang belum terkomputerisasi dan masih menggunakan cara yang konvensional. Dari penelitian ini diharapkan pembuatan sistem informasi yang dihasilkan nantinya akan mampu mengatasi dari sistem yang belum terkomputerisasi (Indah, 2013).

Dalam penelitian yang berjudul Aplikasi Penjualan dan Stok Barang pada Nuansa Elektronik dengan peneliti yang bernama Fendi Nurcahyono memiliki hasil penelitian Toko Ritzca Elektronik Punung, pencatatan dan pengolahan data barang, jumlah dan harga barang, data para supplier, serta data transaksi penjualan masih dilakukan dengan menggunakan tulisan tangan. Kesulitan dalam mencatat dan menghitung banyaknya jenis barang, jumlah barang, maupun besarnya jumlah harga, mengakibatkan data yang diperoleh menjadi kurang akurat. Untuk meningkatkan keakuratan data, diperlukan pembangunan sistem informasi penjualan barang yang terkomputerisasi. Aplikasi pembelian dan penjualan barang ini dibuat dengan menggunakan bahasa Pemrograman Java, software menggunakan NetBeans IDE 7.1.2 sebagai pembuat interface utama dan MySQL sebagai basis datanya (Nurcahyono, 2012).

\section{METODE PENELITIAN}

Metodologi pengembangan sistem yang digunakan Waterfall (Jogiyanto, 2010), dengan tahapan seperti gambar sebagai berikut: 


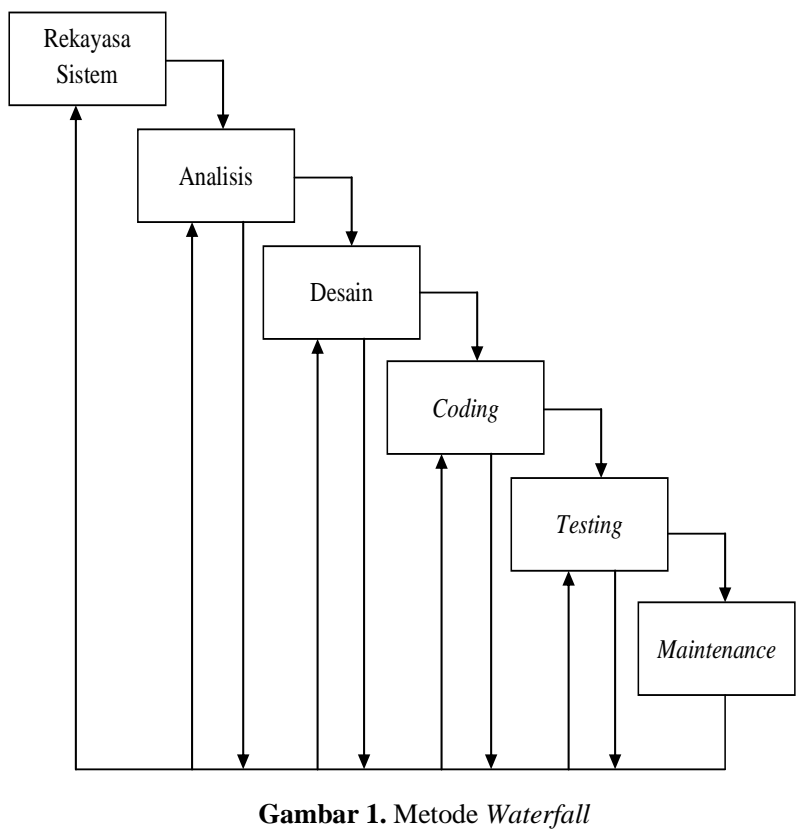

Berikut ini adalah penjelasan dari tahapan-tahapan yang terdapat dalam metode Waterfall:

1. Rekayasa Sistem, merupakan tahap awal dari pembangunan perangkat lunak, yaitu menetapkan segala hal yang diperlukan dalam pelaksanaan pembangunan perangkat lunak dan menentukan apakah sistem benar-benar dibutuhkan.

2. Analisis, merupakan tahap dimana rekayasa perangkat lunak menganalisa hal-hal yang diperlukan dalam pembuatan suatu aplikasi yang akan dibuat.

3. Desain, merupakan tahap penterjemahan dari keperluan data-data yang telah dianalisa kedalam bentuk yang mudah dimengerti oleh pemakai.

4. Coding, adalah tahap penterjemahan data pemecah masalah yang telah dirancang kedalam bahasa pemograman komputer yang telah ditentukan.

5. Testing, merupakan tahap pengujian terhadap perangkat lunak yang telah selesai dibuat untuk menemukan kesalahan-kesalahan atau kekurangan yang terdapat di dalam sistem. Pada pengujian ini peneliti menggunakan pengujian black box. Pengujian black box adalah pengujian aspek fundamental system tanpa memperhatikan struktur logika internal perangkat lunak. Metode ini digunakan untuk mengetahui apakah perangkat lunak berfungsi dengan benar. Pengujian black box merupakan metode perancangan data uji yang didasarkan pada spesifikasi perangkat lunak. Data uji dieksekusi pada perangkat lunak dan kemudian keluar dari perangkat lunak dicek apakah telah sesuai dengan yang diharapkan.

Pengujian black box berusaha menemukan kesalahan dalam kategori:

a. Fungsi-fungsi yang tidak benar atau hilang.

b. Kesalahan interface, kesalahan dalam tampilan layar.

c. Kesalahan pada struktur data atau akses database.

d. Kesalahan performansi, kesalahan inisialisasi dan tujuan akhir.

6. Maintenance, yaitu tahap akhir dimana perangkat lunak yang sudah selesai dan mengalami perubahan atau penambahan sesuai dengan permintaan. Bagian ini merupakan bagian terujung dari siklus pengembangan sistem laporan data administrasi. Pada tahapan ini dilakukan kegiatan corrective maintenance, yaitu mengkoreksi kesalahan pada perangka lunak yang baru diketahui pada saat perangkat lunak dipergunakan. Dengan adanya corrective maintenance terhadap sistem laporan data administrasi, maka kesalahan-kesalahan yang terdapat pada sistem administrasi ini dapat diperbaiki. 


\section{HASIL DAN PEMBAHASAN}

\section{Analisa Permasalahan}

Pada sistem informasi penjualan mebeul di CV Mandiri Furniture ini ternyata mempunyai beberapa kelemahan karena sistem yang digunakan belum sepenuhnya terkomputerisasi. Penelitian data masih dilakukan secara manual dalam pencatatan data penjualan maupun dalam pembuatan laporan. Sehingga proses pencatatan secara manual memerlukan tempat penyimpanan yang sangat luas, akibat kertas yang bertumpuk serta memerlukan waktu yang lama dalam proses pencarian kembali data. Serta Pelayanan terhadap konsumen menjadi tidak efisien dan mungkin akan terjadi kesalahan akibat waktu yang lama dalam pencarian data.

\section{Alternatif Penyelesaian Masalah}

Untuk mencari solusi dalam permasalahan yang ada maka peneliti membuat suatu sistem yang akan membantu dalam menyelesaikan masalah tersebut. Berdasarkan analisa sistem yang sedang berjalan saat ini peneliti melihat beberapa kelemahan dan pokok permasalahan yang terdapat pada sistem penjualan mebeul di atas, maka peneliti memberikan saran beberapa alternatif penyelesaian masalah diantaranya:

Agar tidak terjadi keterlambatan didalam proses pengerjaan informasi, sebaiknya dikoordinasi dengan baik dan terkomputerisasi dengan benar antara sub sistem yang satu dengan yang lainnya, dan sebaiknya CV. Mandiri Furniture membuat rancangan sistem yang dapat meringankan dalam bertransaksi, membuat laporan, mengecek data-data khususnya pada penjualan mebel. Dan file ataupun data yang sudah dikerjakan sebaiknya disimpan ke harddisk ataupun alat penyimpanan data yang lain, dan jika perlu dibuat backup-nya jika saat terjadi kesalahan memiliki cadangan file ataupun data-data. Alangkah baiknya bila komputer yang digunakan untuk memproses data di upgrade, sehingga pemrosesan data tersebut dapat dilakukan lebih baik, cepat (menghemat waktu) dan tepat.

\section{Diagram Konteks}

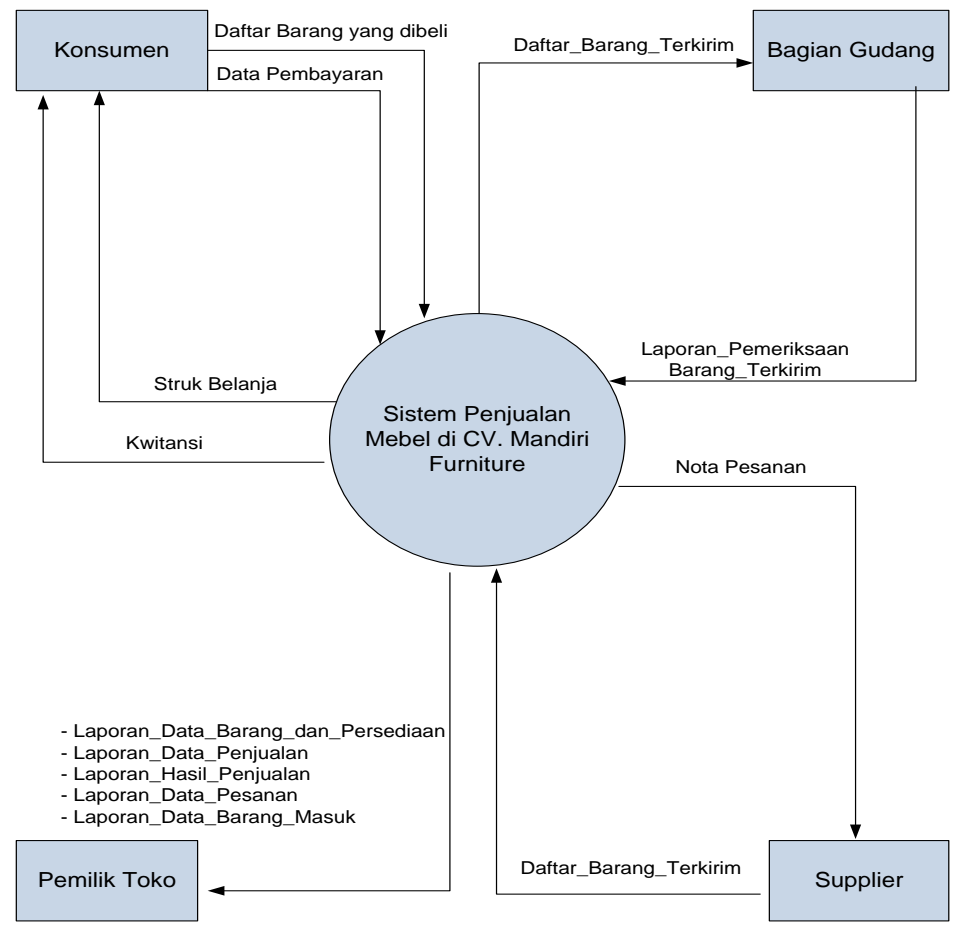

Gambar 2. Diagram Konteks 


\section{Normalisasi}

Normalisasi adalah teknik untuk merancang tabel basis data relasional guna meminimalisir duplikasi data sehingga dapat menjaga basis data dari permasalahan unomaly update (Pahlevi, 2013).

Berikut bentuk normalisasi dari sistem informasi penjualan mebeul di CV Mandiri Furniture:

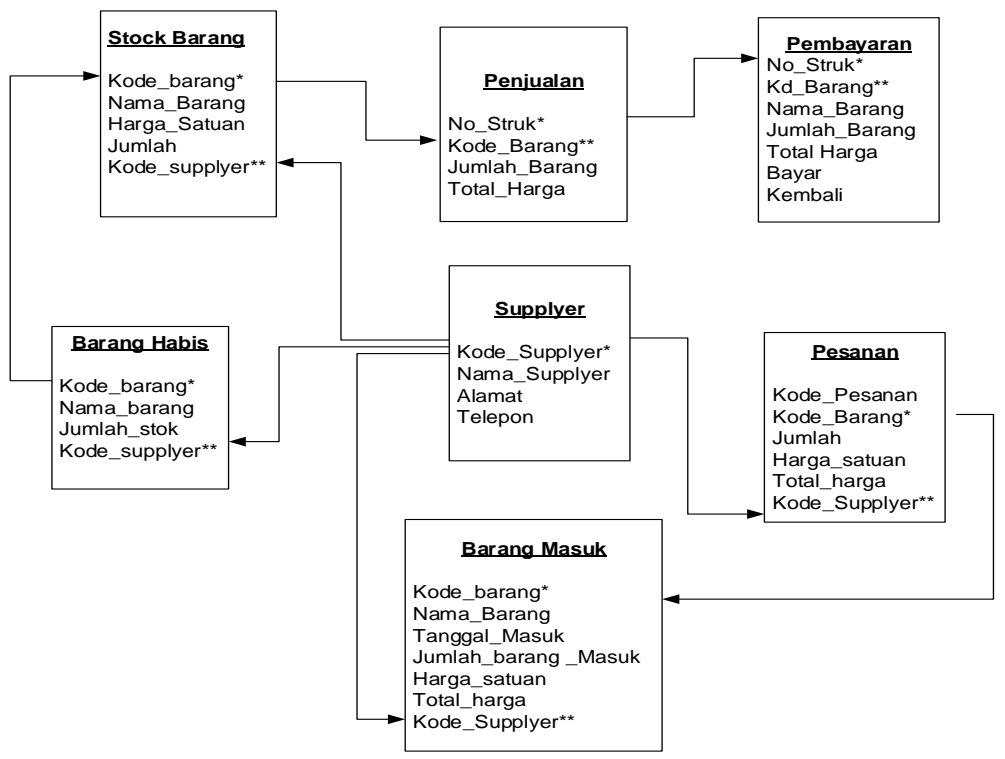

Gambar 3. Normalisasi

\section{Entity Relationship Diagram (ERD)}

Entity Relationship Diagram (ERD) adalah Entity Relationship Diagram (ERD) dikembangkan berdasarkan teori himpunan dalam bidang matematika. ERD digunakan untuk pemodelan basis data relasional (Shalahudin, 2015).

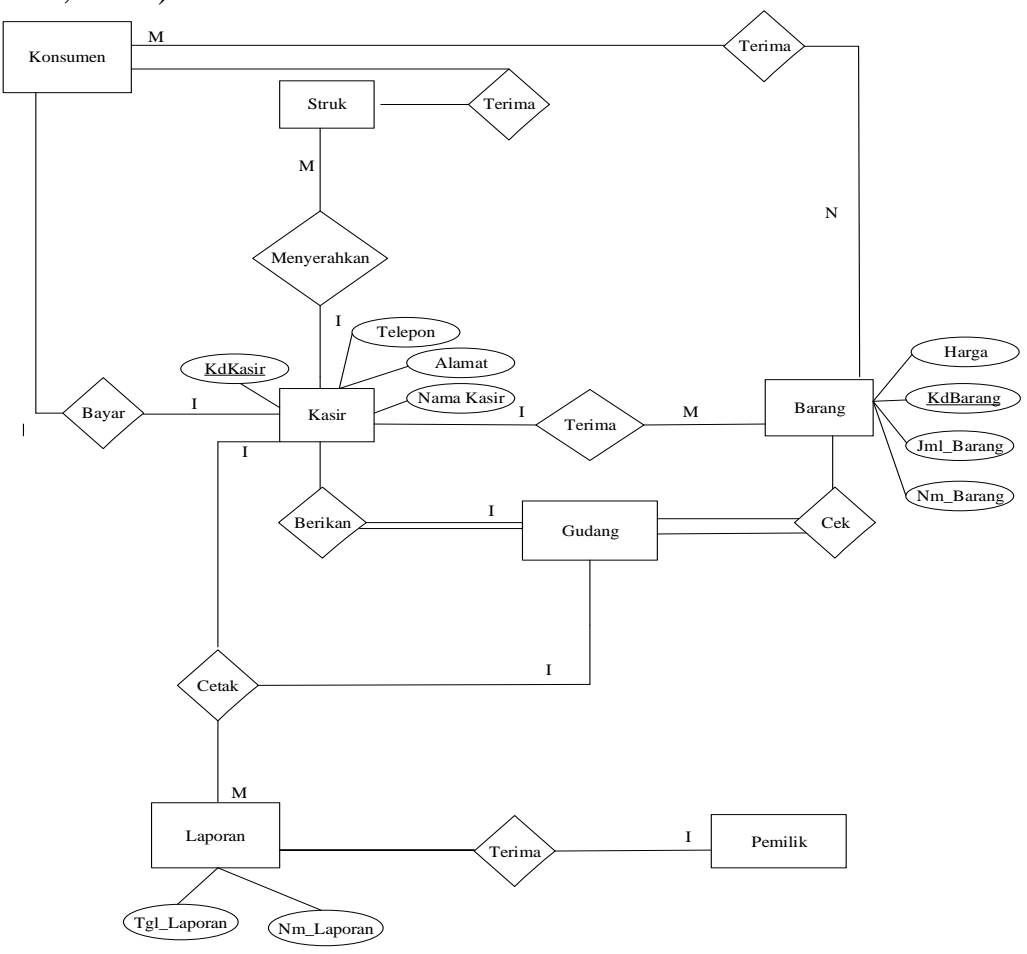

Gambar 4. Entity Relationship Diagram 


\section{Tampilan Layar Sistem}

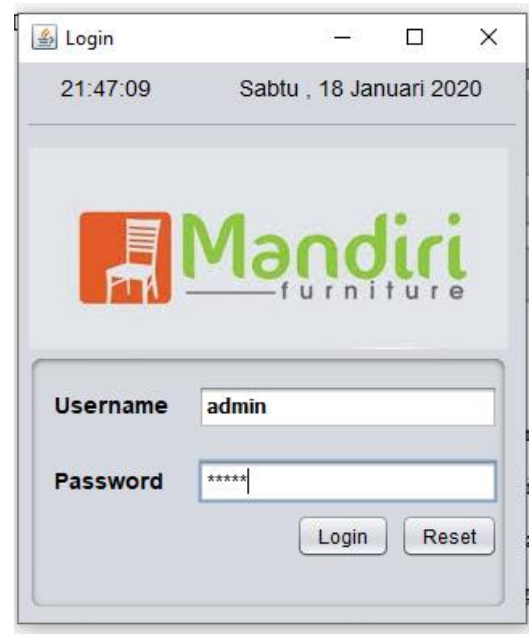

Gambar 5. Tampilan Layar Log In

Tampilan ini terdapat pada awal program. Menu login digunakan sebagai kata kunci sebelum kita memasuki program utama. Agar tidak sembarang orang dapat mengakses program ini. Sehingga dalam Form menu kerahasiaannya tetap terjaga dengan baik. Apabila pengguna dapat memasukkan nama pengguna dan kata kunci dengan tepat, maka menu utama akan tampil dan program siap untuk dijalankan.

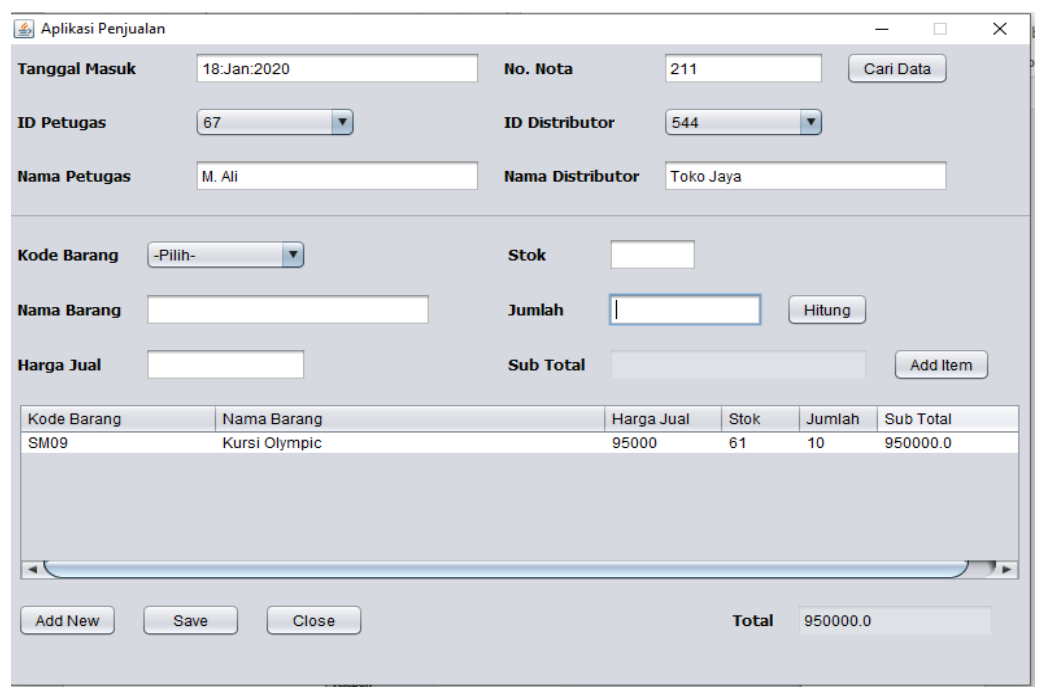

Gambar 6. Tampilan Layar Data Barang Masuk

Layar di atas menampilkan tampilan form data barang masuk. Pada layar form data barang masuk untuk menginput data barang masuk yang terdiri dari Tanggal Masuk, ID Petugas, Nama Petugas, No Nota, ID Distributor, Nama Distributor, Kode Barang, Nama Barang, Harga Jual, Stok, Jumlah, dan Sub Total. 


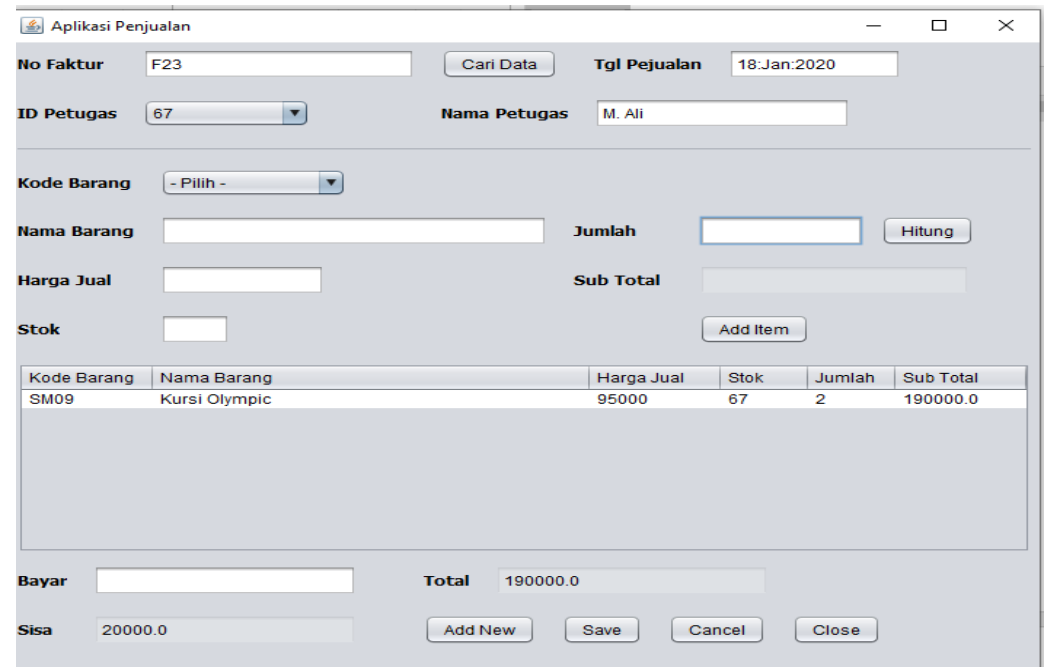

Gambar 7. Tampilan Layar Penjualan

Layar di atas menampilkan tampilan form data penjualan. Pada layar form data penjualan untuk menginput data penjualan yang terdiri dari No Faktur, ID Petugas, Tgl Penjualan, Nama Petugas, Kode Barang, Nama Barang, Harga Jual, Stok, Jumlah, dan Sub Total.

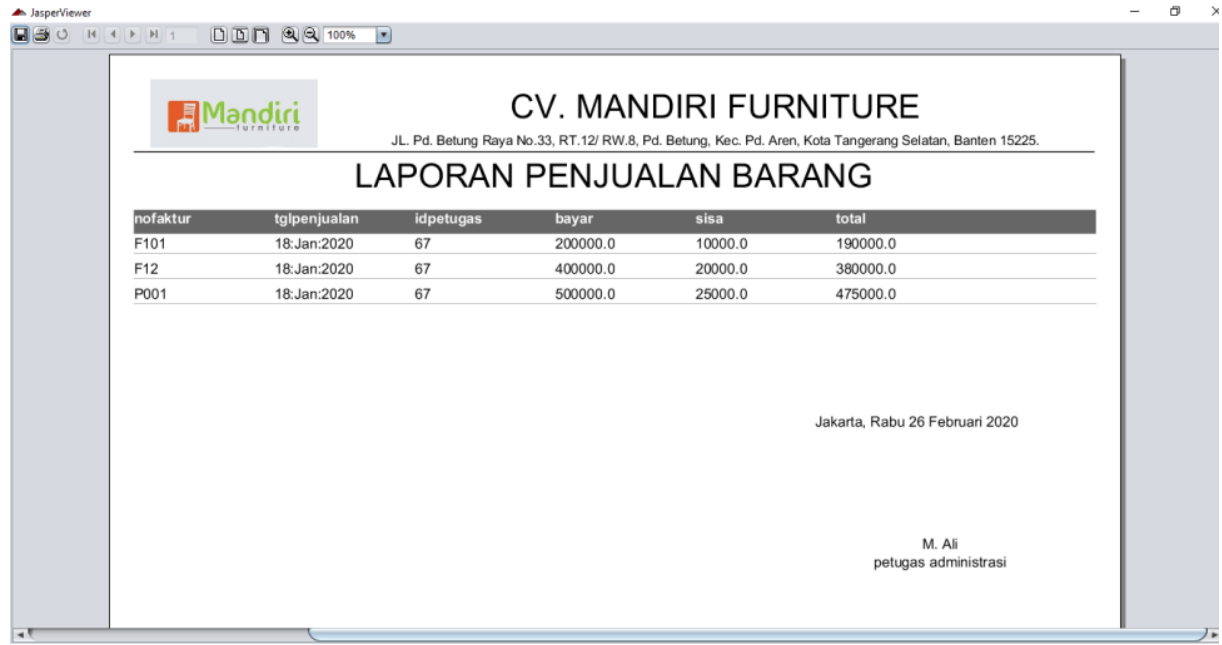

Gambar 8. Tampilan Laporan Data Penjualan Barang

Layar di atas menampilkan tampilan form laporan data penjualan barang. Pada layar form laporan data penjualan barang terdapat informasi data penjualan barang yang terdiri dari No Faktur, ID Petugas, Tgl Penjualan, ID Petugas, Bayar, Sisa dan Total.

\section{SIMPULAN}

Dengan adanya sistem informasi penjualan ini dapat membantu kinerja keuangan terutama dalam melakukan transaksi penjualan dan sistem informasi penjualan ini juga memudahkan proses pembuatan laporan. Sistem informasi penjualan ini dirancang dengan tujuan memudahkan pimpinan dalam memonitoring, mengambil keputusan dan mendapat laporan. 


\section{DAFTAR PUSTAKA}

Indah, I. N. (2013). Pembuatan Sistem Informasi Penjualan Pada Toko Sehat Jaya Elektronik Pacitan. Indonesian Jurnal On Computer Science.

Nurcahyono, Fendi. (2012). Pembangunan Aplikasi Penjualan Dan Stok Barang Pada Toko Nuansa Elektronik Pacitan. Sentra Penelitian Engineering Dan Edukasi.

Jogiyanto. (2010). Analisis \& Desain Sistem. Yogyakarta: Andi Offset.

Pahlevi, D. S. M. (2013). Tujuh Langkah Praktis Pembangunan Basis Data. Jakarta: Elex Media Komputindo.

Shalahudin, A. . R. dan. (2015). Rekayasa Perangkat Lunak Terstruktur dan Berorientasi Objek. Bandung: Informatika Bandung.

Sutabri, Tata. (2012). Analisis Sistem Informasi. Yogyakarta: Andi Offset.

Tantri, T. A. \& F. (2016). Manajemen Pemasaran. Depok: PT Raja Grafindo Persada. 